\title{
Sustainable product design education: engineering students' perceptions and attitudes
}

\author{
Isabel M. João \\ ADEQ, ISEL - Instituto Superior de Engenharia de Lisboa, \\ Instituto Politécnico de Lisboa \\ CEG-IST, Instituto Superior Técnico, \\ Universidade de Lisboa \\ Lisboa, Portugal \\ ijoao@deq.isel.ipl.pt
}

\author{
João M. Silva \\ ADEQ, ISEL - Instituto Superior de Engenharia de Lisboa, \\ Instituto Politécnico de Lisboa \\ CQE, Instituto Superior Técnico, \\ Universidade de Lisboa \\ Lisboa, Portugal \\ jmsilva@deq.isel.ipl.pt
}

\begin{abstract}
Moving towards sustainable development is a global challenge requiring efforts from all the society, but governments and other stakeholders as well as researchers and academics have a central role to aid put in practice the knowledge and tools to enforce the vital changes. This work was developed to better understand the topic of sustainable product design among engineering students given the deficit of such kind of studies in the master courses of our engineering department. Survey data were collected from engineering students enrolled in master courses that have in its syllabus the product design curricular unit. The main objective of the work was to understand the students' perceptions and attitudes in relation to sustainable product design to envisage actions to continually improve the course with the goal of developing students' further knowledge and competencies with the focus on cradle to cradle design strategies.
\end{abstract}

Keywords-sustainable product design, engineering education, assessment, competencies, knowledge

\section{INTRODUCTION}

Achieving sustainable development presents a huge challenge to society being critical to achieve the sustainable development goals and targets by 2030 [1]. Sustainable development was outlined in the 80's of the last century as an opportunity to address global challenges, allowing to reconcile economic development with environmental protection, and an important milestone was the Brundtland report [2] entitled Our Common Future where sustainable development is formulated as: "Development that meets present needs without compromising the ability of future generations to meet their own needs". The role of education in the societal movement towards Sustainable Development (SD) was firstly accentuated with that report and just after it with the Rio Declaration on Environment and Development in 1992 where the environment and SD were put into education and research priorities [3]. The role of education was continuously strengthened and ten years later in $\mathrm{RIO}+10$ in 2002, focus was given to the creation and the reinforcement of networks of science and education for the implementation of Agenda 21 with the aim of achieving global SD. The decade 2005-2014 was named by UNESCO the United Nations Decade of Education for SD [4] and the main goal was to integrate the principles, values and practices of SD in all facets of education and training. Some positions gained prominence and visibility as for example education for sustainable development (ESD) and engineering education for sustainable development (EESD) due to the exigence of a more sustainable future as in terms of environmental integrity and economic feasibility, as in terms of a fair society. The transition to a value creating circular economy will lead to new business models with new frameworks developed to assist practitioners with tools to speed up the move from a linear to a circular model [5]. The evolution of a circular economy also requires changes in consumer behaviour, governmental policies, education models, and several changes at various levels, such as value chains, product service delivery, as well as product design, production, and use and disposal processes [6]. The role of sustainable product design in engineering education is very important in the transition to a circular economy (CE) requiring a transformation in the way people create products and this is very dependent on how people learn and apply those learnings in the real world.

This work was developed to better understand the topic of sustainable product design among engineering students of a Polytechnic Engineering School to explore the students' perceptions and attitudes related to sustainable product design in the master courses offered. This work was targeted to look at the ways that students think in order to develop actions to continuously improve the course and reorient education practices towards sustainability with the goal of providing engineers with further competencies on the design of sustainable products.

\section{Moving From A LINEAR TO A CIRCUlAR DESIGN MODEL}

All kinds of decisions made at the product design phase will significantly impact the use, production and end of life phases, as in terms of energy expenditure as in terms of life duration, maintenance practices, repair, reuse, recycle, upgrade and waste handling. One leading principle of Circular Design (CD) is the inertia principle introduced by Stahel [7] that states: "Do not repair what is not broken, do not remanufacture something that can be repaired, do not recycle a product that can be remanufactured." The inertia principle means minimizing the interventions on the product keeping the product in the original state or as close as possible to the original diminishing environmental costs due to the interventions. The economic and environmental value of the resources is preserved as long as possible, either by increasing the lifetime of the products or by closing the cycle looping them in the System to be reused. The notion of waste in CE tends to be minimized and inexistent if the products and materials could be cycled repeatedly. For a long time, the design of most products had been "linear" meaning that raw materials were used to create a product following the linear "take-make-dispose" model of resources. McDonough and Braungart [8] explain in detail how to achieve their Cradle to Cradle (C2C) design model requiring a radical change in the industry and changing the paradigm of Cradle to Grave $(\mathrm{C} 2 \mathrm{G})$ to this new paradigm 
where more changes need to be done beyond the reduce, reuse, recycle methods. In $\mathrm{CD}$ the resources are uninterruptedly cycled in several ways encouraging the development of products with the goal of upcycling in mind. The idea of upcycling is based on the system of lifecycle development where, when products reached the end of life, they can re-enter the environment as "biological nutrients" or can remain within closed loop industrial cycles as "technical nutrients".

\section{THE HIGHER EDUCATION ROLE TOWARDS SUSTAINABLE DEVELOPMENT}

Education holds a central role in sustainable development and was highlighted in the 80's with the Brundtland report and just after it with the 1992 Earth Summit in Rio de Janeiro, where a powerful international consensus began, and sustainable development was put into education priorities. The international community agreed that education is central to achieving sustainable development and learning is essential to reorient education around the three pillars of sustainable development: economic, social, and environmental. This consensus gained even more prominence in 2002 in Johannesburg with the World Summit on Sustainable Development where the international community reinforced the significance of education attaining sustainable development. Education alone does not have the capacity to make our planet more sustainable, but it is certain that without education and learning about sustainable development this goal cannot be achieved. Education plays a central role in changing practices and behaviours that enable us to create a more just society with economically and environmentally conscious feasibility reason why as said before, the United Nations General Assembly declared the period from 2005 to 2014 the United Nations Decade for Sustainable Development [4]. The education is indeed vital to better understand the interdependence and vulnerability of our planet life support systems and the natural resources upon which the living beings depend and so it is of utmost importance to benefit from education and training in order to learn the principles, values, practices and lifestyles essential for a sustainable future [9].

A rapid evolution in debate occurred with the need to incorporate sustainable development knowledge and skills into engineering education and prominence was given to ESD and EESD due to the important role engineers are expected to play in planning and developing projects that are able to preserve natural resources sustaining human and natural environments in a cost efficient way. The EESD Barcelona Declaration [10] defined how higher education institutions and educators should respond to the need of the society and prepare future professionals who should be able to use their expertise not only in a scientific or technological context, but equally for wider environmental, social and political contexts. Birne et al. [11] made a review of the international progress towards EESD providing an overview of emerging sustainability skills placing them in the context of the engineering institutions declarations as well as initiatives, policies and codes of ethics. At RIO +20 , the United Nations Conference on SD the international community decided to integrate SD more actively into education ahead from the United Nations decade of education for sustainable development with the growing international recognition of ESD as an essential part of education [12].

Issues related with $\mathrm{SD}$, sustainability and $\mathrm{CE}$ have been a regular theme in somehow recent engineering education conferences as EDUCON 2014 with the theme "Engineering Education towards Openness and Sustainability" or the Congress organized by the World Federation of Engineering Organizations WCEE2015 with the theme "Engineering Education for Sustainable Development", the SEFI annual conference 2017 with the theme "Education Excellence for Sustainable Development" or the conference EESD 16 with the theme "Building a circular economy together" just to name a few. Despite the escalating attention in engineering education for $\mathrm{CE}$ there is still a long way to go to entrench $\mathrm{CE}$ concepts in engineering education, and the shift to $\mathrm{CE}$ must also be supported by the education system with the integration of CE into school and university curriculums [13]. Some studies have approached on how to embed CE in higher education [14-17] but there is still a long way to go to properly address the challenge of unsustainable production and consumption.

\section{THE RELEVANCE OF SUSTAINABLE PRODUCT DESIGN IN THE TRANSITION TO A CIRCULAR ECONOMY}

All kinds of decisions made at the product design phase will significantly impact the use, production and end of life stages, as in terms of energy expenditure as in terms of life duration, maintenance practices, repair, reuse, recycle, upgrade and waste handling. The implementation of the ecodesign Working Plan 2016-2019 [18] was a sign of the European Commission role to the promotion of the circular design of products with eco-design labelling measures for several products setting out, not only energy efficiency measures, but also including rules on resource efficiency requisites as for example availability of spare parts, repairing easiness, and simplicity of end of life treatment. The creation of the requisites for products in areas such as durability, reparability, design for disassembly, upgradeability, information and easier to reuse and recycle, greenhouse gas and other emissions shows the potential of eco-design measures to substantially contribute to circular economy. According to Ellen MacArthur Foundation [13] circular economy should "be restorative and regenerative by design. The recovery of materials and products is not only addressed at the end of use, but is enabled at the design level" meaning that the product design has a central role in restorative and regenerative industrial systems with the goal of keeping products at their highest value, meaning that the economic and environmental value of the resources is preserved as long as possible. Also, in 2019 the European Commission adopted a comprehensive report on the implementation of the Circular Economy Action Plan [19]-which presents the main achievements and outline the main future challenges facing our economy on the way to a climate neutral with minimization of pressure on natural resources and ecosystems emphasizing the relevance of sustainable product design at the beginning of products' life cycle and its significance for guaranteeing circularity.

\section{INVESTIGATING STUDENTS'PERCEPTIONS AND ATTITUDES RELATED TO SUSTAINABLE PRODUCT DESIGN}

Ensuring that our students are well prepared with the appropriate knowledge and competences to meet the 
operational role that engineers are expected to play in affecting the future of our planet is recognised as indispensable.

\section{A. Purpose of the study and research questions}

Provided the interest and involvement of Higher Education Institutions in creating and improving sustainable product design curricula, the main goal of this research is to investigate students' perceptions of sustainable product design and understand how the product design course impacts a variety of attitudes towards sustainable design and examine how sustainable product design education impacts engineering student outcomes. It is also our goal to identify differences within and across gender and type of master course attended by students and also understand if there are differences in students with different backgrounds. The following research questions were addressed: a) What are the perceptions of the engineering students in relation to the product design program being offered? b) How is sustainable design in the students' interest? c) What are engineering students' perceptions of their sustainable product design related abilities? d) What is the attitude of students when facing actions to be developed to reduce the environmental impact of products? e) How do students globally evaluate their sustainable product design knowledge?

\section{B. Method and Results}

In order to explore the students' thoughts related to sustainable design in the master courses offered by a department of a Polytechnic Engineering School we decided to investigate the students perceptions' of sustainable design and how the Product Design course impacts a variety of attitudes towards sustainable design. The study was performed in the master courses that include Product Design in their study plans. Master course A (McA) is the Quality and Environmental Engineering master course that provides advanced knowledge in environmental technologies and quality engineering techniques combined with management methods focused on organizational excellence. The syllabus of the McA focuses on themes of recognized importance for the planning, control, improvement of processes and products with emphasis on the efficient use of resources and the use of technologies appropriate to the best business practices in a systemic vision of sustainability. Master course $\mathrm{B}(\mathrm{McB})$ is the Chemical and Biological Engineering master course $(\mathrm{McB})$ that aims to give a solid preparation in the specialty sciences of Chemical and Biological Engineering, in order to provide students with the skills to apply their knowledge in new situations, understanding the phenomena involved and managing to design and/or simulate the behaviour of chemical, and biological processes or related processes. The $\mathrm{McB}$ is strongly focused on the design, development, optimization and management of processes, complemented by a laboratory component, transversal to the various scientific areas.

The survey developed was based on a questionnaire that was administered to the students of the respective master course. The assessment instrument was designed to examine the engineering students' perceptions and attitudes in relation to sustainable product design education with the main goal of developing future actions to increase students' knowledge and competencies in sustainable product design.
The questionnaire consists of some demographic questions related to gender and age of the participants as well as the information about their previous bachelor graduation, and information about previously extracurricular training in product design. Also, a group of items belonging to the following item categories was addressed:

Perceptions of Product Design Program - To investigate the perceptions of the engineering students in relation to Product Design Program being offered a total of ten items of this class were selected (i.e. Discussion of topics of sustainable innovation in the scope of Product Design; Product design fosters circular economy; Students are encouraged to develop skills for sustainable design; Topics related to sustainable behaviours are discussed; Product Design is presented as a career option; Students should learn more about circular economy; There must be more opportunities to contact designers; Examples are given to encourage sustainable product design; workshops facilitate the acquisition of knowledge in sustainable design; product design must respond creatively to social issues).

Interest - To investigate students' interest in sustainable product design a total of seven items of this class were selected (i.e. I consider myself sufficiently informed on the topic of circular economy; I recognize the importance of Environmental Management Systems (EMSs); I am informed about compliance with dangerous substances; I recognize the importance of carbon footprint and / or other environmental impacts; Sustainability topics in the curriculum can help me to get a job; The engineer needs skills in the field of sustainable design; The engineer must know how to communicate the value creation provided by sustainable design).

Abilities - To investigate students' skills related to sustainable product design total of seven items of this class were taken into consideration (Ability to conduct Life Cycle Assessment studies; Ability to Implement Environmental Management Systems; Ability to evaluate the merits of different product designs; Ability to assess risk in product design; Ability to generate different product concepts; Ability to use selection techniques for new product designs; Ability to translate needs into technical specifications).

Actions - To investigate the attitude of students when facing actions to be developed to reduce the environmental impact of products a total of eight items were selected (i.e. Reduction of the amount of materials to be used; Reduction of different types of materials to use; Local search for materials or production to reduce transportation; Reduced packaging; Reduction of energy consumed by the product; Carrying out life cycle assessment studies; Obtain product environmental certification; Use of eco-labels). Also, an open-ended question was made related with other actions to be taken.

Expertise - A global evaluation question to evaluate students' knowledge perception on sustainable product design.

The questionnaire was designed to take about 10 minutes to complete and 5-point Likert scales were used: strongly disagree (SD), disagree (D), neither agree/nor disagree (NN), agree (A) and strongly agree (SD) and also a performance scale: poor (P), bellow average (BA), average (A), above average (AA) and excellent (E). The questionnaire was distributed to the students by the faculty members involved 
in the research study and the response rates were $72 \%$ for master course A (McA) and $77 \%$ for master course B (McB). Table I presents the characterization of the engineering students that participated in the survey.

The total number of students enrolled in the two master courses is 56 with a total of 25 students in McA and a total of 31 students in McB. The overall response rate was $75 \%$ to a rate of $72 \%$ for $\mathrm{McA}$ and $77 \%$ for $\mathrm{McB}$. The proportion of women is globally higher when compared with men with an almost $3 / 5$ of women to $2 / 5$ of men and this proportion is similar in both master courses with approximately the same identified proportion of women and men as represented in table I.

The collected data allowed to study differences within and across gender (i.e. male and female) and type of master course (i.e. McA and McB). Also, the differences across different graduate courses taken by students before joining their master's courses was explored. To determine statistically significant differences between master courses or between gender or previous graduate course on the ordinal dependent variable (i.e. data on Likert scales) a rank based nonparametric test was used (i.e. the Kruskal-Wallis H test). The main reason to use a rank based nonparametric test is related to the response scales used in the questionnaire, that is Likert scales where the students were asked to specify their level of agreement with a given statement by means of an ordinal measurement scale. To determine whether the differences between the medians are statistically significant, the $\mathrm{p}$-value was compared to the significance level of 0.05 meaning a $5 \%$ risk of concluding that a difference exists when there is no actual difference.

In relation to the global evaluation question to evaluate students' knowledge perception on sustainable product design no statistical differences were found between gender nor between the students of the two master courses nor distinct previous degrees. Table II presents the percentage of students that rated their knowledge on sustainable design issues as average or above average.

Although no statistically significant differences were found between the independent variables gender, master course that students attend or previous degree courses acquired by the students, it can nevertheless be concluded that globally $90 \%$ of the students rate their knowledge on sustainable design as average or above average.

TABLE I. DESCRIPTIVE ANALYSIS OF ENGINEERING MASTER STUDENTS INCLUDED IN THE SURVEY

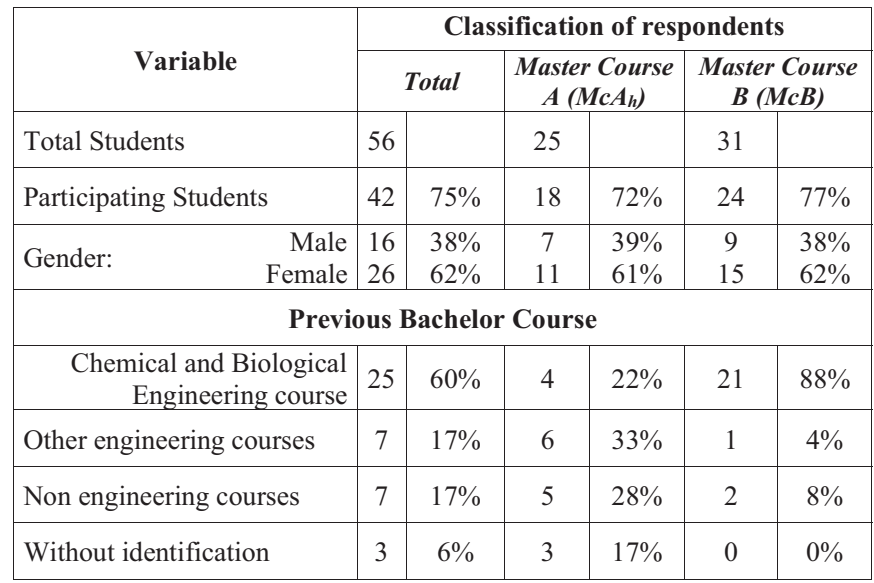

TABLE II. STUDENTS' KNOWLEDGE PERCEPTIONS ON SUSTAINABLE PRODUCT DESIGN

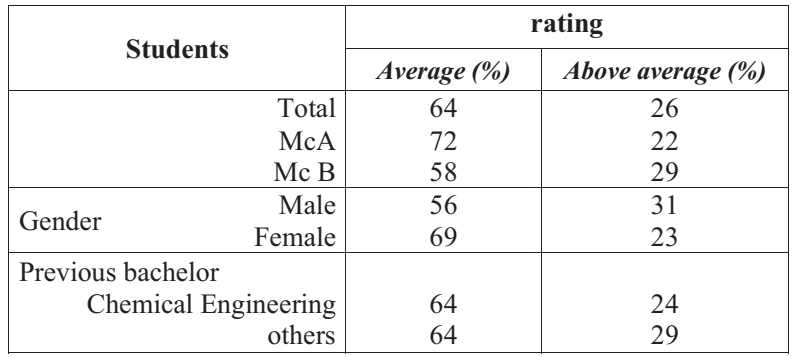

To the research question a) What are the perceptions of the engineering students in relation to the product design program being offered? The ten items evaluated by the students were checked to look for statistically significant differences between gender, between the two master courses as well as between the previous bachelor course of the students.

The first independent variable selected was the type of master course and significant differences were observed with item "Product design promotes circular economy" with significant differences between the courses $(p<0.035)$ with $83 \%$ of McA students that agree or strongly agree compared with $65 \%$ of $\mathrm{McB}$. In relation to the second independent variable selected, the gender, significant differences was found for item "Topics related to sustainable behaviours are discussed" ( $(p<0.036)$ with $69 \%$ of females that agree or strongly agree when compared to $33 \%$ of male that agree or strongly agree. Also, for item "Examples are given to encourage sustainable product design" $(\mathrm{p}<0.033)$ with $69 \%$ of female and $31 \%$ of male that agree or strongly agree, and for the item "Product design must respond creatively to social issues" ( $\mathrm{p}<0.010)$ between the two-independent group of students. In relation to previous bachelor courses differences were found between chemical and biological engineering and other engineering or non-engineering courses statistically significant differences were found for item "Product design is presented as a career option" with $(\mathrm{p}<0.035)$ and for item "There must be more opportunities to contact designers" with $(\mathrm{p}<0.035)$ and also for item "Examples are given to encourage sustainable product design" with $(\mathrm{p}<0.030)$.

Figure 1 presents the students' perceptions in relation to the ten items of the research question a) where significant differences were observed between the independent groups studied.

Students from McA, the Quality and Environmental Engineering master course more strongly agree that product design promotes circular economy when compared with students from the Chemical and Biological Engineering master course. When comparing males and females we can observe that females more strongly agree that topics related to sustainable behaviours are discussed and that examples are given to encourage sustainable product design. Also, females more strongly agree that product design must respond creatively to social issues. In relation to previous bachelor courses, students from courses other than chemical engineering have a higher perception in relation to the presentation of product design as a career option or in relation to the existence of examples given in the course that encourage sustainable product design. The same students 
Product design promotes circular economy

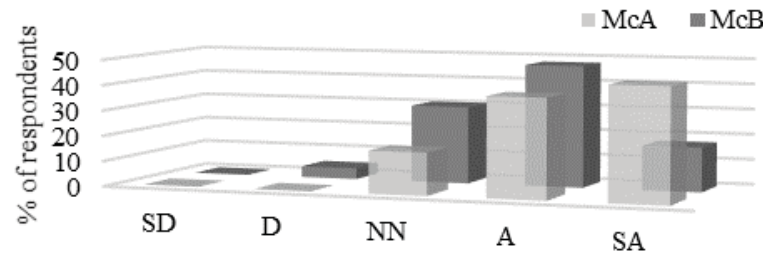

Topics related to sustainable behaviours are discussed

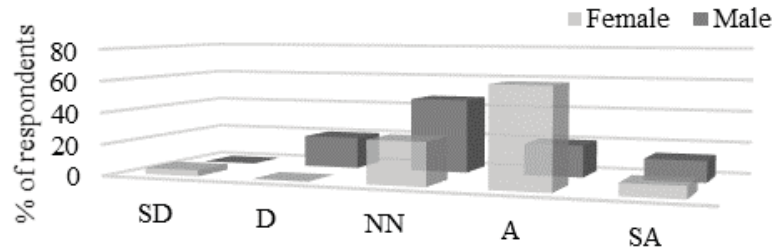

Examples are given to encourage sustainable product design

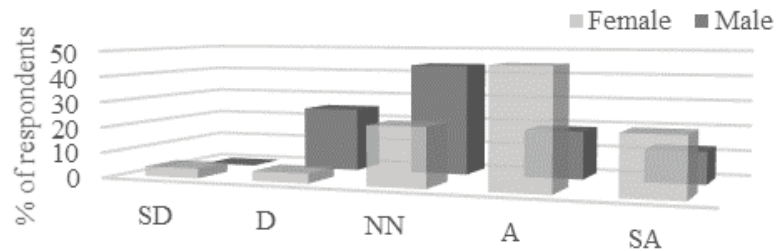

Product design must respond creatively to social issues

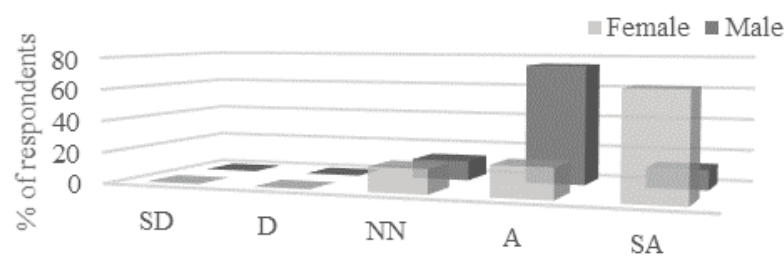

Product design is presented as a career option

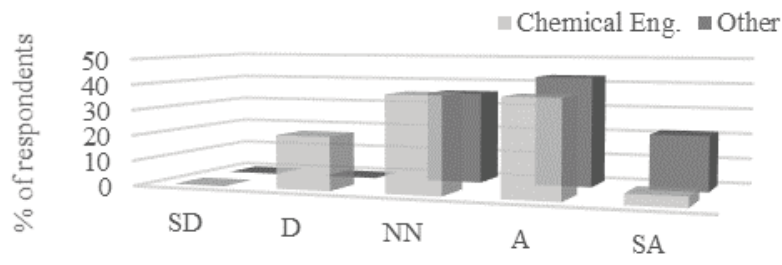

There must be more opportunities to contact Designers

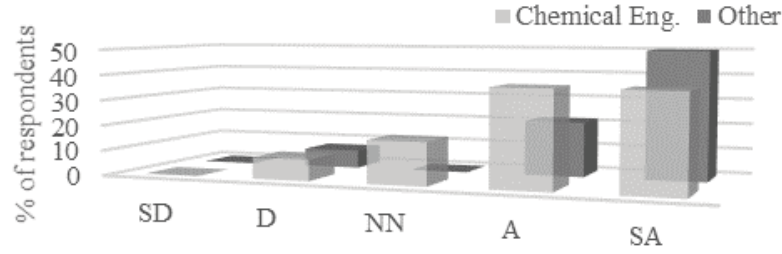

Examples are given to encourage sustainable product design

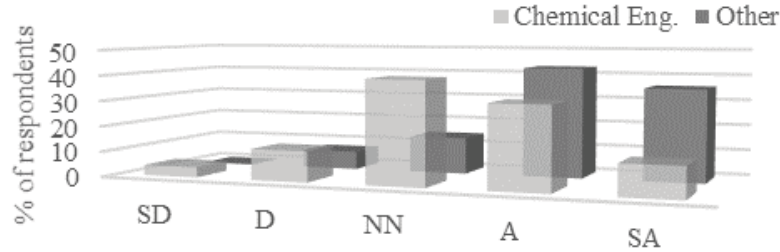

Fig. 1. Students perceptions in relation to the items of the research question a) where significant differences were observed among the independent groups studied, i.e. master course, gender and previous degree. also think that there should be more opportunities to contact the designers. In relation to research question b) How is sustainable design in the students' interest? the differences between master courses, gender and previous bachelor courses were studied in relation to the seven statements (i.e. items) of the class. Significant differences exist for the two master courses in the statement "I consider myself sufficiently informed on the topic of circular economy" $(\mathrm{p}<0.001)$ with $78 \%$ of $\mathrm{McA}$ that agree or strongly agree compared with $21 \%$ of $\mathrm{McB}$. Concerning the independent variable gender, no statistically significant differences were found for any of the seven statements and the same conclusions can be drawn for the independent variable previous bachelor courses.

Figure 2 presents the students' interest in sustainable product design where significant differences were observed between McA and McB. Students from the Quality and Environmental Engineering master course more strongly agree to be informed on the topic of circular economy when compared with the students of Chemical and Biological Engineering master course. In relation to the independent variables gender and previous bachelor courses no significant differences were found between male and female and among the previous bachelor courses regarding the seven items in the class.

Concerning research question c) What are engineering students' perceptions of their sustainable product design related abilities? Statistical differences were tested in relation to the independent group master courses, gender (i.e. female (F) and male (M)) and previous bachelor courses. For the independent variable Master courses significant differences exist in the item "Ability to conduct LCA studies" $(\mathrm{p}<0.003)$ with $39 \%$ of McA that answered above average or excellent when compared with $17 \%$ of McB. Also, differences exist in the item "Ability to implement EMS" with $(\mathrm{p}<0.012)$ with $44 \%$ of McA when compared to $21 \%$ of $\mathrm{McB}$. In relation to the independent variable gender no significant differences were found between male and female regarding the seven items in the class. Also, in relation to the independent variable previous bachelor courses no statistically significant differences were found among the groups.

Figure 3 presents the students' perceptions in relation to the seven items of the research question c) where significant differences were observed between $\mathrm{McA}$ and $\mathrm{McB}$.

Table III presents the percentage of students (i.e. globality of students, students by course, and students by gender) that felt to have poor or below average skills concerning the 7 items related to students' abilities.

I consider myself sufficiently informed on the topic of circular economy

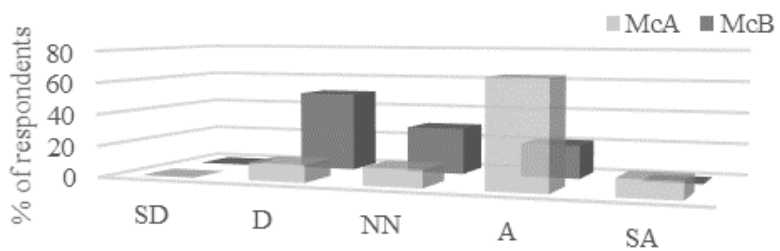

Fig. 2. Students' perceptions in relation to the items of the research question b) where significant differences were observed between master course A and master course B. 
Ability to conduct Life Cycle Assessment studies

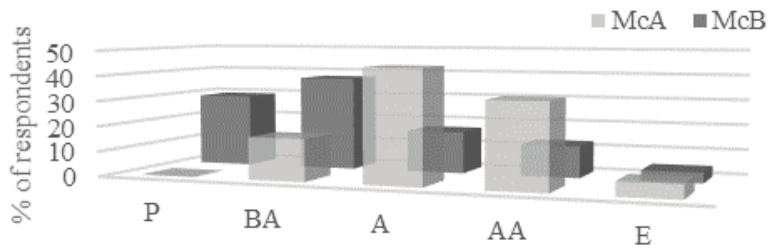

Ability to Implement Environmental Management Systems

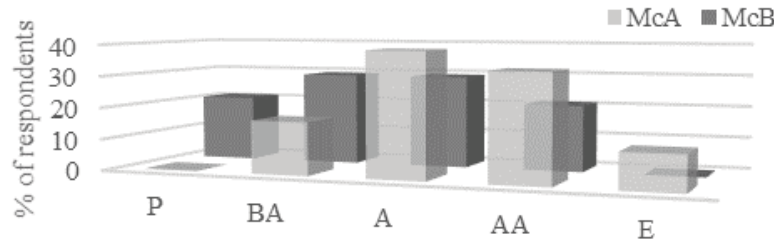

Fig. 3. Students perceptions in relation to the items of the research question c) where significant differences were observed between master course A and master course B.

TABLE III. STUDENTS' PERCEPTIONS OF THEIR SUSTAINABLE PRODUCT DESIGN RELATED ABILITIES

\begin{tabular}{|l|c|c|c|c|c|}
\hline \multirow{2}{*}{ Items } & \multicolumn{5}{c|}{ Ability } \\
\cline { 2 - 6 } & \multirow{2}{*}{$\begin{array}{c}\text { Total } \\
(\%)\end{array}$} & \multicolumn{2}{|c|}{$\begin{array}{c}\text { Mc } \\
(\%)\end{array}$} & \multicolumn{2}{c|}{$\begin{array}{c}\text { Gender } \\
(\%)\end{array}$} \\
\cline { 3 - 7 } & 45 & 17 & 67 & 46 & 44 \\
\hline 1) Conduct LCA studies & 36 & 17 & 50 & 35 & 38 \\
\hline 2) Implement EMS & 19 & 28 & 13 & 15 & 25 \\
\hline 3) Evaluate the merits of distint PD & 19 & 11 & 25 & 12 & 31 \\
\hline 4) Assess risk in PD & 19 & 28 & 13 & 19 & 19 \\
\hline 5) Generate different product concepts & 24 & 17 & 29 & 15 & 38 \\
\hline 6) Use selection technique for new PD & 21 & 22 & 21 & 19 & 25 \\
\hline $\begin{array}{l}\text { 7) Translate needs into technical } \\
\text { specifications }\end{array}$ & 21 & & 25 \\
\hline
\end{tabular}

* Poor + Below average

Based on the students' perceptions of their sustainable product design skills it is worth to note that they rate themselves better with the ability to evaluate the merits of different product designs and in the assessment of risk in PD as well as in the generation of different product concepts. Regarding the implementation of EMS or the conduction of Life Cycle Assessment studies the students globally evaluate themselves poorly, but there are significant differences between the students of both master courses. The students of Quality and Environmental Engineering master course rate their abilities higher when compared to the students of the Chemical and Biological Engineering master course. In relation to gender, there are not significant differences between male and female where globally they perceive their abilities better in items 3) to 7) when compared with items 1) and 2).

In relation to research question d) What is the attitude of students when facing actions to be developed to reduce the environmental impact of products? the differences among master courses, gender and previous bachelor courses were studied in relation to the eight statements. In relation to the first independent variable studied (i.e. master course) significant differences occur in the statement "Reduction of different types of materials to use" $(\mathrm{p}<0.025)$ with $94 \%$ of students from McA that agree or strongly agree when compared to $58 \%$ of students from McB. Also, for the item "Carrying out lifecycle assessment studies" $(\mathrm{p}<0.025)$ significant differences occur between the students of both master courses with $94 \%$ of students from McA that agree or strongly agree when compared to $75 \%$ of students from $\mathrm{McB}$. In relation to gender statistically significant differences exist $(\mathrm{p}<0.004)$ concerning item "Obtain product environmental certification" with $88 \%$ of female students that agree or strongly agree when compared to $69 \%$ of the male students that agree or strongly agree.

In relation to previous bachelor courses differences were found between chemical and biological engineering and other engineering or non-engineering courses statistically significant differences were found for item "Reduce packaging" ( $\mathrm{p}<0.021)$, and for item "Reduction of energy consumed by the product" $(\mathrm{p}<0.036)$ and also for the item "Carrying out lifecycle assessment studies" ( $<<0.046)$.

Table IV presents the percentage of students (i.e. total number of students, students by course, and students by gender) that agree or strongly agree with the following actions to be developed to reduce the environmental impacts of the products.

Based on the students 'attitudes concerning the action to be developed to reduce environmental impacts of the products they tend to agree or strongly agree with all the statements regarding the actions to develop. However, there are some differences between the two master courses with the students of Quality and Environmental Engineering giving more emphasis to the "Reduction of different types of materials to use" as well as "Carry out lifecycle assessment studies" when compared to the students of Chemical and Biological master course. Also, female students give more emphasis to the action "Obtain product environmental certification" when compared to male.

Figure 4 presents the students' attitudes in relation to the eight items of the research question d) where significant differences were observed among the independent groups studied.

TABLE IV. STUDENTS'ATTITUDES RELATED TO ACTIONS TO BE DEVELOPED TO REDUCE ENVIRONMENTAL IMPACTS OF THE PRODUCTS

\begin{tabular}{|l|c|c|c|c|c|}
\hline \multirow{2}{*}{ Items } & \multicolumn{5}{c|}{ Action } \\
\cline { 2 - 6 } & $\begin{array}{c}\text { Total } \\
(\%)\end{array}$ & \multicolumn{2}{|c|}{$\begin{array}{c}\text { Mc } \\
\text { (\%) }\end{array}$} & \multicolumn{2}{c|}{$\begin{array}{c}\text { Gender } \\
(\%)\end{array}$} \\
\cline { 3 - 6 } & $\boldsymbol{A}$ & $\boldsymbol{B}$ & $\boldsymbol{F}$ & $\boldsymbol{M}$ \\
\hline $\begin{array}{l}\text { 1) Reduction of the amount of } \\
\text { materials tobe used }\end{array}$ & 86 & 94 & 79 & 81 & 94 \\
\hline $\begin{array}{l}\text { 2) Reduction of different types of } \\
\text { materials to use }\end{array}$ & 74 & 94 & 58 & 73 & 75 \\
\hline $\begin{array}{l}\text { 3) Local search of material or } \\
\text { production to reduce transportation }\end{array}$ & 88 & 89 & 88 & 88 & 88 \\
\hline $\begin{array}{l}\text { 4) Reduce packaging } \\
\text { 5) Reduction of energy consumed } \\
\text { by products }\end{array}$ & 90 & 94 & 88 & 88 & 94 \\
\hline $\begin{array}{l}\text { 6) Carry out Lifecycle assessment } \\
\text { studies }\end{array}$ & 83 & 94 & 75 & 88 & 75 \\
\hline $\begin{array}{l}\text { 7) Obtain product environmental } \\
\text { certification }\end{array}$ & 81 & 78 & 83 & 88 & 69 \\
\hline 8) Use of Ecolabels & 83 & 89 & 79 & 85 & 81 \\
\hline
\end{tabular}

* Agree + Strongly agree 
Reduction of different types of materials to use

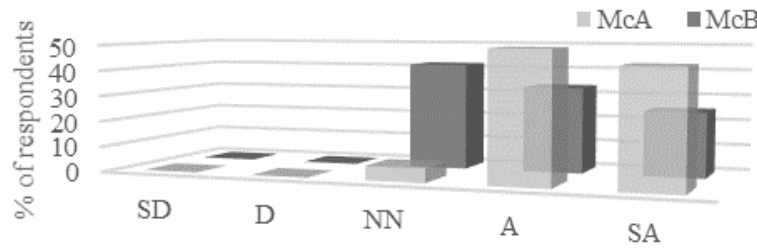

Carrying out life cycle assessment studies

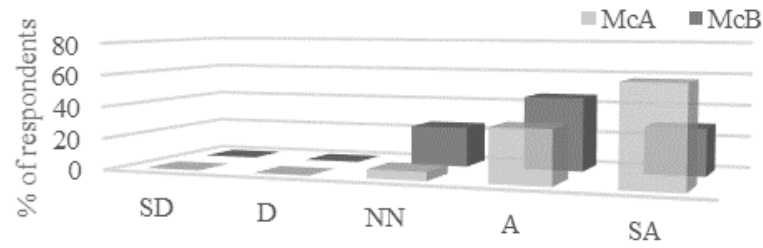

Obtain product environmental certification

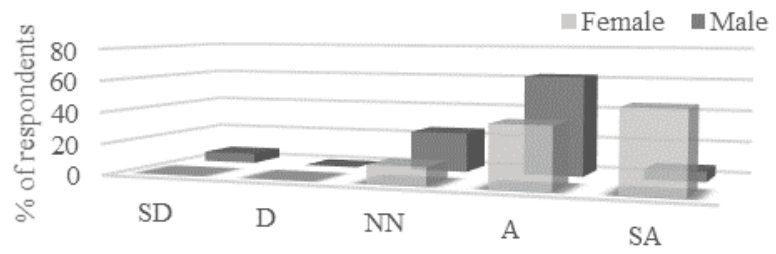

Reduced packaging

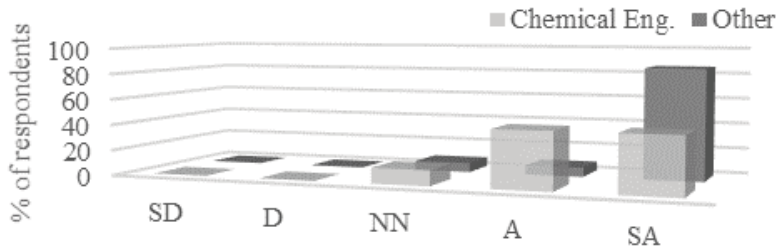

Reduction of energy consumed by the product

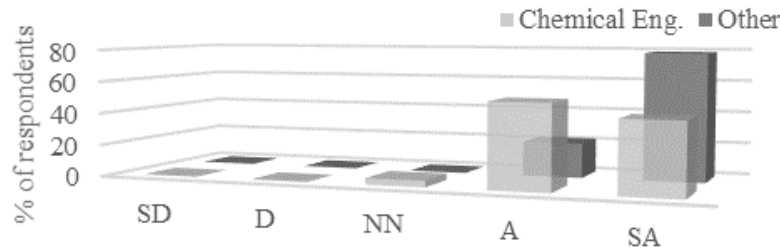

Carrying out life cycle assessment studies

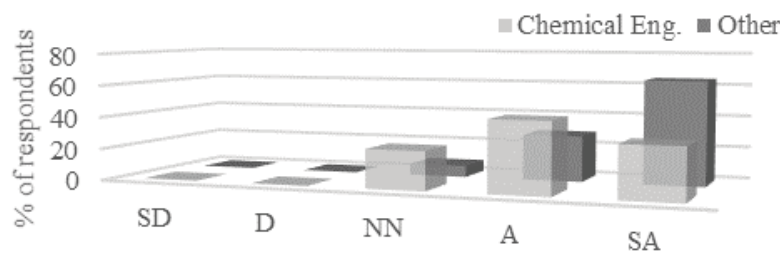

Fig. 4. Students perceptions in relation to the items of the research question d) where significant differences were observed among the independent groups studied, i.e. master course, gender and previous degree.

\section{CONCLUSIONS}

The study summarizes data involving students' perceptions and attitudes regarding sustainable product design and took place in the engineering courses of the chemical engineering department of a Polytechnic Engineering School with the students who attended the product and process design course in the academic year of 2018-2019.
Overall, $90 \%$ of the engineering students that answered the questionnaire rated their knowledge perception on sustainable design issues covered in the product design program as average or above average and no statistically significant differences were found between the independent variables gender, master course that students attend or previous degree courses acquired by the students.

However, in relation to the first research question addressing the perceptions of the engineering students in relation to the product design program being offered some differences were found mainly within male and female with female having a higher perception that topics related with sustainable behaviours are discussed and that examples are given to encourage sustainable product design and that product design must respond creatively to social issues were female more strongly agree with the statement. This is in accordance with Zelezny et al. [20] where they found that compared to male, female have higher levels of socialization to be other oriented and socially responsible. Students from McA when compared with McB more strongly agree that product design promotes circular economy, and this can be justified by the differences between the syllabus of the two master courses. The students of Quality and Environmental Engineering master course (i.e. McA) have greater interaction with the topic of circular economy within the contents of the various curricular units of the course when compared to the Chemical and Biological Engineering master course (i.e. McB). This is in accordance with the answers of the students in relation to the second research question related to students' interest regarding the sustainable design topic where almost $4 / 5$ of the McA students consider themselves sufficiently informed on the topic of circular economy when compared to $1 / 5$ of the students from $\mathrm{McB}$.

In relation to the third research question related with students 'perceptions of their sustainable product design related abilities the answers evidenced that all of them rate themselves average or above average with almost $4 / 5$ of the students seeing themselves as having the ability to translate needs into technical specifications or generate different product concepts or using selection techniques for new product designs or having the ability to assess risk in product design or even evaluating the merits of different product designs. However, statistical differences occur between McA and $\mathrm{McB}$ with the ability to conduct LCA assessment studies or the ability to implement EMS where Quality and Environmental Engineering master students have higher perceptions related with their abilities when compared with Chemical and Biological Engineering master students, what is in line with the syllabus of the two courses and was expected to occur.

In relation to actions to be developed to reduce the environmental impacts of the products statistical differences occurred between the two master courses in relation to some statements as the different type of materials to use or the need to carry out lifecycle assessment studies where the students of McA are more aware of the need to develop actions of this kind due to the subjects that are covered in the master's program. Also, female students more strongly agree when compared to the male that the obtaining of product environmental certification is an action to be developed to reduce the environmental impact of the products. This is in accordance with past gender studies where it was found that 
females social network represents an important foundation for environmental collective force [21]

The results provide understanding into the topic and are a starting point for further research and for the implementation of strategies to improve competencies on sustainable product design with the focus on cradle to cradle $(\mathrm{C} 2 \mathrm{C})$ paradigm with upcycling in mind.

\section{REFERENCES}

[1] United Nations, About Sustainable Development Goals https://www.un.org/sustainabledevelopment/sustainabledevelopment-goals/ (accessed on October 20, 2019).

[2] World Commission on Environment and Development, Our Common Future. Oxford: Oxford University Press, 1987.

[3] United Nations General Assembly, Rio Declaration on Environment and Development. The United Nations Conference on Environment and Development, Rio Janeiro, 3-12 June 1992.

[4] UNESCO, UN decade to education sustainable development. https://en.unesco.org/themes/education-sustainable-development/ what-is-esd/un-decade-of-esd (accessed on October 16, 2019).

[5] M. Lewandowski, "Designing the business models for circular, economy-towards the conceptual framework," Sustainability, vol. 8(43), January 2016.

[6] Buren et al. 2016 N. van Buren, M. Demmers, R. Heijden and F. Witlox, "Towards a Circular Economy: The Role of Dutch Logistics Industries and Governments," Sustainability, vol. 8(647), 2016.

[7] Stahel,W.R. 2010. The performance economy, 2nd ed. London: Palgrave Macmillan.

[8] McDonough, W.; Braungart, M. Cradle to Cradle: Remaking the Way We Make Things; North Point Press: New York, NY, USA, 2002.

[9] Combes, B.P.Y.,'The United Nations Decade of Education for Sustainable Development (2005-2014): learning to live together sustainably. Applied environmental Education and communication $4: 3,215-219,2005$
[10] Barcelona Declaration (2004). Engineering Education in Sustainable Development Conference, Barcelona, october 29, 2004. Available online: http://eesd15.engineering.ubc.ca/declaration-of-barcelona/

[11] Byrne,E., Desha, C., Fitzpatrick, J., Hangroves, K., "Engineering Education for Sustainable Development: a review of international Progress", 3rd International Symposium for Engineering Education, University of Cork, Ireland, 2010.

[12] Rio +20. https://sustainabledevelopment.un.org/rio20

[13] Ellen MacArthur Foundation, Towards the circular economy: Economic and business rationale for an accelerated transition, November 2015. Available online: https://www.ellenmacarthur foundation.org/assets/downloads/TCE_Ellen-MacArthurFoundation_9-Dec-2015.pdf (accessed on October 11, 2019).

[14] Kirchherr J., Piscicelli, L., "Towards an education for the circular economy (ECE): five teaching principles and a case study", Resources, Conservation \&Recycling 150, 1-12, 2019.

[15] Ormazabal, M., Jaca, C., Prieto-Sandoval, V., Lleo,A., "Developing engineering students engagement with circular economy practices", 3rd International Conference on Higher Education Advances, HEAd'17, Universitat Politecnica de Valencia, Valencia, 2017.

[16] Kopnina, H. ,"Circular economy and cradle to cradle in educational pretice", Journal of integrative environmental sciences, 15:1, 119134,2018

[17] Cappuyns, V., Stough, T., "Dealing with societal Challenges of a circular economy in engineering education", Engineering education for sustainable development, Bruges, Belgium, 2016.

[18] European Commission, Communication from the commission: Ecodesign working plan 2016-2019, Brussells, November 2016.

[19] European Commission, communication from the commission to the European Parliament, the Council, the European Economic and Social Committee and the Committee of the Regions on: The implementation of the circular economy action plan, Brussels, March 2019

[20] Zelezny, L.C., Chua, P.-P., Aldrich, C., "Elaborating on gender differences in environmentalism", Journal of Social Issues, 56:3, 443457, 2000.

[21] Agarwal, B., "Conceptualizing environmental collective action: why gender matters", Cambridge Journal of Economics, 24:3, 283-310, 2000 . 